\title{
OLHARES EM PROGRESSO, OLHARES EM PROCESSO: \\ Uma experiência de vídeo participativo com jovens que habitam um espaço fronteiriço ${ }^{1}$
}

Ana Zanotti $^{2}$

O ponto de partida para esta narração é minha vivência convergente entre antropologia social e produção audiovisual. Primeiro, como integrante do departamento de vídeo em uma instituição pública teleducativa na província de Misiones, Argentina, tentando resolver as maiores dificuldades em experiência educacional; e, mais recentemente, como cineasta independente de documentários, embora sempre na base de um controle rígido sobre o próprio processo audiovisual.

Quando, no final de 2005, recebi um convite de Alina Frapiccini ${ }^{3}$ para me juntar ao capítulo provinciano do programa, "Un Minuto por Mis Derechos" 4 - já que Misiones estava prestes a entrar no esquema nacional da UNICEF - pensei muito sobre este pedido, dado que seria um desafio absolutamente novo, uma mudança horizontal do meu papel costumeiro de diretora para o de facilitadora, durante um processo extensivo, intensivo, colaborativo de construção audiovisual envolvendo a participação de todo um conjunto de adolescentes e adultos jovens como grupo alvo. $O$ resultado foi uma experiência participativa "caleidoscópica", na concepção de Shirley White (White, 2003: 8), mudando cor e forma de acordo com quem está a manuseando. O presente artigo pretende guiar o leitor através de alguns dos seus momentos, todos eles passos valiosos no entendimento que talvez não haja maior segredo para ser bem sucedido, do que um atitude aberta e de consideração em relação as pessoas com as quais nos juntamos.

É o início de 2006. Pela segunda vez, uma experiência participativa de vídeo, envolvendo jovens e seus direitos, está prestes a começar em várias províncias argentinas.

\footnotetext{
${ }^{1}$ Artigo originalmente publicado em inglês em 2008 na revista Nordicom foi devidamente autorizada sua publicação em português pelos editores Thomas Tufte, Flor Enghel e Ulla Carlsson.

${ }^{2}$ Universidade Nacional de Misiones, Argentina.

3 Diretor do Projeto na "KINE Foundation", uma ONG cultural e educacional selecionada pela UNICEF Argentina para conduzir seu programa nacional, "Un Minuto por Mis Derechos".

${ }^{4}$ A experiência também ofereceu uma base contextual e metodológica para meu Trabalho de Projeto, a fim de completar meu mestrado em "Comunicação para o Desenvolvimento" na Universidade de Malmö (Suécia). Para esse trabalho produzí um documento escrito e audiovisual sobre esta experiência de pesquisa participativa, já que também consegui manter um registro completo do processo inteiro em vídeo digital.
} 
Esta narração de empoderamento se dá em Misiones, um território fronteiriço no nordeste da Argentina entre Paraguai e Brasil.

Tradicionalmente, Argentina tem sido considerada um país rico dentro do contexto sulamericano. Mas passou a ser extremamente vulnerável a mudanças na economia internacional durante estes últimos 25 anos, em particular durante os anos 90 e o inicio deste milênio, com dramático custo de desemprego e exclusão social.

O modelo econômico neoliberal se espalhou e se estabeleceu firmemente durante a última década do século 20, quase ameaçando de morte a educação pública, saúde pública e cultura - uma grande fonte de orgulho no passado - já que muitas funções e empresas públicas acabaram em mãos privadas, e uma grande abertura ao mercado internacional levou a um novo modelo social, deixando vastas porções da sua sociedade civil à própria sorte, dramaticamente jogada no domínio incerto do mercado informal.

UNICEF (Argentina) e KINE Fundação Cultural e Educativa, uma instituição ONG argentina iniciou, já em 2005, um programa chamado "Un Minuto por Mis Derechos” com o objetivo de tratar essas dificuldades no campo da infância e juventude. Resgata sua origem na colaboração internacional OneMinutesJr estabelecida em novembro 2002 pela European Cultural Foundation, UNICEF e o Sandberg Institute. OneMinutesJr é um vídeo de 60 segundos feito por jovens que produzem suas próprias mensagens, se expressando e, no processo, aprendendo habilidades valiosas de mídia.

A versão argentina desta intervenção sociocultural a define como:

(...) oficinas de produção audiovisual nos centros comunitários, escolas, clubes e igrejas, nos quais crianças e jovens compartilham espaços para dialogo sobre suas aspirações, realidades e problemas, refletindo sobre eles como pessoas com direitos. (...) Fazem com que suas vozes sejam ouvidas; dão uma boa olhada no mundo que os circundam, e procuram maneiras para transformá-lo.

(Kine, 2006)

No ano seguinte, o programa ampliou seu escopo com o objetivo de desenvolver as regiões economicamente atrasadas, sendo Misiones uma das províncias a hospedar o programa.

Antes de avançar para a narração de algumas particularidades da própria experiência, seria útil apontar algumas das linhas básicas do programa a fim de permitir a sustentabilidade e continuidade das suas realizações: 
- Oficinas audiovisuais motivam cooperação de sujeitos sociais - ao nível público, privado e de comunidade - na direção de suporte para a construção de uma sociedade mais justa, com crescente inclusão social e econômica, e ainda, cedendo ao pensamento coletivo criativo;

- Treinar jovens cineastas - tanto em habilidades sociais quanto técnicas - abre capacidades e aptidões para refletir sobre a vida comunitária do modo geral;

- Cultura - os filmes curtos produzidos e disseminados encorajam cidadania, reforçam identidades locais e amor próprio, e até contribuem para o estreitamento dos efeitos do preconceito e estigma entre povos.

A primeira tarefa era de convocar uma equipe com dois facilitadores em cada província, que seriam auxiliados por um ou dois assistentes.

(...) profissionais locais com um conhecimento em linguagem audiovisual e experiência trabalhando com crianças e jovens (...) integrando equipes de diversos profissionais locais, todos relacionados a comunicação, educação e cultura.

(Kine, 2006)

Todos os facilitadores assistiram um curso de treinamento de duração de uma semana em Buenos Aires, antes de começar o trabalho de fato, com a intenção de se conhecerem, compartilhar visões a respeito dos seus campos de prática e conhecimento, como também suas preocupações e expectativas. Como alguns facilitadores estavam no programa pelo segundo ano, suas contribuições foram particularmente valiosas para os novatos, embora provavelmente nenhuma das experiências compartilhadas combinaria exatamente com as situações participativas por vir. Alguns conteúdos específicos também foram fornecidos por profissionais externos experientes nas questões de direitos humanos, habilidades de mobilização e técnicas de animação audiovisual.

Em seguida, os facilitadores assumiriam a responsabilidade de selecionar localmente instituições parceiras hóspedes, como também as locações onde duas oficinas semanais seriam realizadas, cada uma envolvendo mais de 25 participantes jovens (idade: 14-21). 
Aos facilitadores foram permitidos ampla liberdade - dentro das linhas gerais estabelecidas pelo programa - para tomar decisões sobre os dois assuntos, desde que lidassem com jovens vivendo em ambientes sócio-economicamente inseguros.

E o propósito global do programa foi desenvolver oficinas com duração de 5 meses de treinamento prático sobre a realização de filmes, para construir um processo fértil de reflexão sobre os direitos dos jovens, enquanto progredindo constantemente em direção ao objetivo final: elaborar 10 peças de vídeo de um minuto de duração, contando como jovens lidam com questões de identidade e como eles se percebem como pessoas detentoras de direitos e gozando de respeito em suas próprias comunidades.

Nosso grupo de trabalho reuniu uma professora e jornalista (Mirian), uma estudante de comunicação social (Lara) e eu. Nossas contribuições conjuntas provenientes de várias origens representariam uma combinação equilibrada de comunicação, educação, arte e cultura durante as atividades.

A província de Misiones é uma área fronteiriça no extremo nordeste da Argentina, um terreno estreito, situado entre Paraguai e o sul do Brasil, e formando com estes uma região de cultura compartilhada de laços fortes, construídos ao longo das suas historias em comum.

Fronteiras são singulares (...) por que são grandes laboratórios de integração direta entre populações com contato físico e geográfico. E é assim por que é nas fronteiras onde contato de verdade se desenvolve entre pessoas concretasde verdade e não no meio de regramentos abstratos.

(Abinzano, 1998)

Ao longo da sua história, este território regional tem sido um terreno comum para uma experiência compartilhada. A cadeia cronológica de padrões sócio- culturais de um extenso e antigo povoado aborígine, desde os tempos pré-coloniais, seguido pelo peso dos séculos de conquista européia, representado regionalmente nas missões jesuítas, após o qual Misiones pôde traçar com clareza sua denominação atual; em seguida, uma coexistência inquieta durante o século 19, até os tempos de guerra e batalha que deu origem a 3 naçõesestado, traçando linhas onde sempre houve continuidade. 
A região aparece como uma sucessão de camadas sobrepostas concernente a sistemas de atividade e maneiras de lidar com terra e o uso de espaço (...), uma historia comum, um ecossistema compartilhado; dilemas produtivos, ambientais e agrários semelhantes; marginalidade relativa similar.

(Abinzano, 1998)

Além disso, o século 20 foi uma era de imigração intensa para a região inteira alemães, poloneses, ucranianos, escandinavos, russos, italianos, japoneses, entre outras nacionalidades impulsionadas por guerra e condições de pobreza. Portanto, o cenário social e cultural delineia um espaço peculiar nas áreas de fronteira, com as marcas de encontros transculturais enraizados profundamente no dia a dia.

Assim, o conceito de "região" é inteiramente significativo para retratar este espaço: um que contem fronteiras ao invés de ser restringido por elas.

Como resultado dessa mescla de configurações, a vida evolui em um cenário contínuo de interculturalidade.

Por interculturalidade entenderemos o dialogo simétrico e relações entre pessoas, práticas, crenças, idiomas, produtos, sociedades e processos sociais, todos eles inseridos nas tradições culturais diferenciadas.

(Reguillo, 2002: 5)

Zonas fronteiriças permitindo fluência de dialogo dinâmico e debate. Nem sempre completamente reconhecidos ou aceitos; talvez nem mesmo politicamente "correto". Um equilíbrio precário, uma vontade obstinada para perseguir a necessidade de ser, sentir e fazer do seu "próprio" modo.

Turbulência (...) permite nominar o não nominado: ansiedade, incerteza, inquietação vaga, barulho ensurdecedor e caótico vindo de um mundo passando por processos de reconfiguração (...) Como colocaríamos a questão sobre interculturalidade sem relacioná-la a este ambiente de dissoluções, de ruptura, de implosões? Como pensaríamos sobre os desafios urgentes pelos quais a comunicação deveria aprimorar o dialogo e os espaços para encontros entre os diferentes?

(Reguillo, 2002: 1-4)

A questão do idioma - essencial à cultura, essencial à identidade - está relacionada diretamente com sua proximidade às fronteiras. A confrontação de idiomas oficiais espanhol e português na região, ambos idiomas dos conquistadores - com a diversidade de 
variedades "menores" sendo amplamente usadas e produzidas nos espaços fronteiriços, se somam um outro aspecto na reflexão sobre interculturalidade, de como a questão do poder é diáriamente exercida na vida das pessoas.

\begin{abstract}
Validade e prestígio na fala não depende da gramática, mas das relações de poder. (...) A fala pode ser ou válida, em vigor, aceitável, legitima, ou então, excluída, inaceitável, insignificante, ilegítima, de acordo com as opções adotadas por aqueles no poder. E estas opções se cristalizam nas políticas linguísticas (...) Políticas linguísticas democráticas pressupõem uma ética de expor com clareza os regulamentos do jogo e decisões centralizadoras, em torno da tolerância de diferenças.
\end{abstract}

(Camblong et al., 1996: 4-5)

Um idioma vive e funciona na interação humana. Assim, o diálogo deveria manter a estrutura ideal para permitir que novos significados, novas palavras, novos mundos surgissem - como ambos os estudiosos de comunicação, Camblong (Arg.) e Reguillo (Mex.) sugerem - através do encontro de todas as vozes em conversação aberta, respeitosa e criativa.

Isto também foi nossa intenção como facilitadores no programa, "Un Minuto por Mis Derechos" em Misiones.

A fim de espelhar o contexto cultural, estas foram as locações selecionadas para ambas as oficinas:

- El Soberbio, uma cidade rural pequena fronteiriça ao Brasil, na outra margem do rio, com forte influência da cultura e idioma deste vizinho. Um ambiente natural privilegiado, com muita pouca presença de instituições nacionais, passando por um processo de migração fluente e não estruturada através do fronteiriço Rio Uruguai.

- Villa Cabello, um subúrbio na periferia de Posadas - a capital da província, próximo do Paraguai - concentrando um terço da população de Misiones - em torno de um milhão de habitantes. Atualmente, Posadas está altamente afetada pela barragem de Yacyreta, um enorme projeto hidrelétrico binacional no Rio Paraná, forçando uma relocação em massa dos habitantes ribeirinhos para uma série de assentamentos uniformes e densamente povoados.

Todas as 4a. feiras dirigíamos para El Soberbio, $250 \mathrm{~km}$ ao norte de Posadas, e 
todos os sábados nos reuníamos em Villa Cabello para avançar com as atividades de oficina. Os diferentes contextos de ambas as locações nos permitiriam contribuições paralelas a respeito das semelhanças e diferenças, de forma que cada processo poderia representar um retorno interessante para o outro.

Uma vez decidida suas locações, nós concordamos sobre a seleção de duas escolas secundárias públicas como espaços físicos para nossas reuniões semanais, embora os participantes não sejam necessariamente seus estudantes. O Ministério da Educação da província aceitou nossa oferta de bom grado, e - no caso de El Soberbio - colaborou fornecendo o combustível para as 20 viagens.

Quanto à tecnologia envolvida, KINE nos emprestou uma videocâmara digital para treino prático de filmagem. As escolas selecionadas deveriam fornecer computadores com recursos básicos de processamento para exercícios audiovisuais, enquanto seus diretores deveriam permitir todos os participantes - até aqueles que não são estudantes delas usufruir da utilização dos seus laboratórios ICT. Uma tarefa nada fácil de realizar.

Maximo, o diretor da escola em El Soberbio esteve muito entusiasmado sobre as novas perspectivas, visto que lugares pequenos e remotos dificilmente são bem posicionados na agenda oficial de educação para iniciativas inovadoras. Em geral, os diretores contam principalmente com seu próprio comprometimento e habilidade como representantes de suas comunidades para negociar adequadamente fora do nível local. Portanto, fomos realmente bem-vindos na sua escola, a única pública de nível secundária na cidade.

Em Villa Cabello a situação foi bastante diferente. A escola selecionada só nos permitiu acesso às suas instalações através de outra instituição - CAJ (Centro de Atividades para Juventude) - desenvolvendo suas atividades aos sábados, quando não havia atividades escolares formais.

Andy, o coordenador do CAJ em Villa Cabello, era a contraparte do Maximo em El Soberbio. Um organizador apaixonado e enérgico, ele se tornou nosso parceiro chave na criação e sustentação de um ambiente aberto e adequado, assim como condições confiáveis para que esse complexo processo se desenvolvesse conjuntamente.

Conhecimento - conteúdo, o "mundo" - é apreendido na relação com o outro, como Paulo Freire coerentemente advoga por toda sua vasta teoria e prática educacional. Ele tem 
uma clara consciência que é uma intenção política; educação em si acarreta um procedimento e propósito político. Ele fala extensamente sobre a percepção crítica da realidade, o processo de desvendar a "leitura" no sentido de adquirir conscientização, e, portanto, permitir transformação, o "reescrever" do mundo.

É muito interessante seguir a segunda linha literária (Freire, 1994), em que ele revive sua Pedagogia dos Oprimidos enquanto fervorosamente apóia a necessidade de adicionar "esperança" - um sonho - na luta para refazer o mundo.

Fazendo-se e refazendo-se no processo de fazer a história, como sujeitos e objetos, mulheres e homens, virando seres da inserção no mundo e não da pura adaptação ao mundo, terminaram por ter no sonho também um motor da história. Não há mudança sem sonho como não há sonho sem esperança. (...) A história não se imobiliza, não morre. Pelo contrário, continua. A compreensão da história como possibilidade e não determinismo, a que fiz referência neste ensaio, seria ininteligível sem o sonho, assim como a concepção determinista se sente incompatível com ele e, por isso, o nega.

(Freire, 1994: Cap. 3)

A questão do horizontal e o vertical é também levantada. Autoritarismo é "aprendido" durante experiências reais em nossa vida cotidiana, circunstâncias que precisamos para reconhecer, revelar e reaprender através da participação horizontal num diálogo genuíno, estabelecido respeitosamente com o outro.

Aí está uma das tarefas da educação democrática e popular, da Pedagogia da esperança -
a de possibilitar nas classes populares o desenvolvimento de sua linguagem (...) sua
linguagem, que, emergindo da e voltando-se sobre sua realidade, perfile as conjecturas,
os desenhos, as antecipações do mundo novo. Está aqui uma das questões centrais da
educação popular - a da linguagem como caminho de invenção da cidadania. (Freire, 1994: Cap. 1)

E com o propósito de compor/edificar esta cidadania, há também novos conteúdos que certamente têm que ser transmitidos; conhecimento preciso oriundo de campos específicos ou disciplinas que o educador precisa adotar como uma responsabilidade vertical despertadora, embora cedendo ao ritmo de todos. A grande diferença no que ele chama de "educação bancária", é que o processo deveria iniciar do que todo mundo é e sabe. 
É preciso que o(a) educador(a) saiba que o seu "aqui" e o seu "agora" são quase sempre o "lá" do educando, Mesmo que o sonho do(a) educador(a) seja não somente tornar o seu "aqui-agora", o seu saber, acessível ao educando, mas ir mais além de seu "aqui-agora" com ele ou compreender, feliz, que o educando ultrapasse o seu "aqui", para que este sonho se realize tem que partir do "aqui" do educando e não do seu. No mínimo, tem de levar em consideração a existência do "aqui" do educando e respeitá-lo. No fundo, ninguém chega lá, partindo de lá, mas de um certo aqui. Isto significa, em última análise, que não é possível ao(a) educador(a) desconhecer, subestimar ou negar os "saberes de experiência feitos" com que os educandos chegam à escola.

(Freire, 1994: Cap. 2)

A contribuição do Freire para educação e comunicação participativas é tão imensa que apontar apenas para um punhado de princípios conceituais orientadores, significa abrir um modo bem consciente para se aproximar, se juntar e firmemente começar a refletir e partir para ação.

Isto é basicamente o que tentamos fazer neste caminho para o empoderamento. Trabalhar na base da esperança, sonho, diálogo, cuidado com a palavra e o mundo do outro, lidando com o vertical significativo e com o horizontal encorajador como nossos procedimentos de abordagem.

Então lá estávamos, tendo pela frente um itinerário de 40 sessões repletas- 20 pessoas por oficina - cada uma de 4 horas, durante a qual nos dedicaríamos a essa nova tarefa desafiadora e provocante.

Tivemos muitas coisas a nosso favor - liberdade para trabalhar, um trabalho expressivo pela frente, uma equipe motivada de facilitadores, alguma colaboração institucional local - e um fator significativo que atuou contra: a necessidade de terminar este processo complexo em 5 meses, com o requisito essencial de ter de 8 a 10 minutos de vídeo prontos para exibição no sexto mês, e exibição nacional no sétimo mês após o início do programa.

A programação apertada tornou particularmente difícil a realização de uma convocação adequada para "preencher as vagas" atribuídas a cada oficina, principalmente em El Soberbio, onde foram alocados recursos de combustível estritamente para as 20 sessões. Portanto, sozinhos não podíamos realizar essa parte importante do processo e tivemos que depender dos representantes das instituições parceiras como responsáveis pelas convocações efetivas. Em Villa Cabello, tal situação foi facilmente solucionada, dado que os centros CAJ já desenvolvem sua intervenção social nos ambientes socioeconomicamente atingidas. Sendo assim, acabamos tendo um grupo numeroso de jovens das cidades dos 
arredores, ou dos "bairros" em Posadas. Mas, em El Soberbio, tivemos uma campanha cara-a-cara e pelo rádio local - a fim de alcançar mais jovens, além daqueles que freqüentam a própria escola secundária. Após o primeiro mês, o grupo definitivo foi finalmente formado, incluindo uns poucos adolescentes vindos das cercanias rurais.

Alguns fatos descritivos sobre os jovens.

\section{$\underline{\text { Participantes por Faixa Etária e Gênero - } 2006}$}

El Soberbio

\begin{tabular}{|c|c|c|c|}
\hline $\begin{array}{c}\text { Faixa } \\
\text { Etária }\end{array}$ & Alunos & Alunas & Total \\
\hline $\mathbf{1 4 - 1 6}$ & 4 & 3 & $\mathbf{7}$ \\
\hline $\mathbf{1 7 - 1 8}$ & 1 & 5 & $\mathbf{6}$ \\
\hline $\mathbf{1 9 - 2 1}$ & 3 & 0 & $\mathbf{3}$ \\
\hline Total & $\mathbf{8}$ & $\mathbf{8}$ & $\mathbf{1 6}$ \\
\hline
\end{tabular}

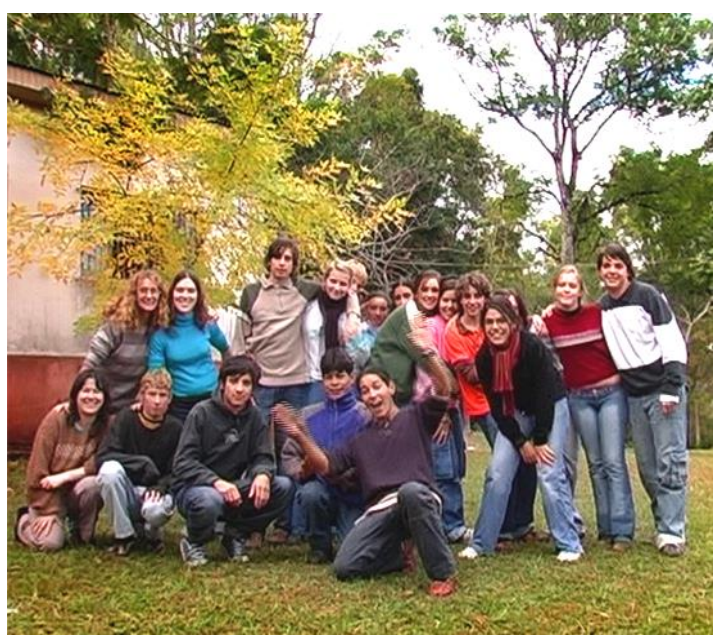

Villa Cabello

\begin{tabular}{|c|c|c|c|}
\hline $\begin{array}{c}\text { Faixa } \\
\text { Etária }\end{array}$ & Alunos & Alunas & Total \\
\hline $\mathbf{1 4 - 1 6}$ & 4 & 0 & $\mathbf{4}$ \\
\hline $\mathbf{1 7 -} \mathbf{1 8}$ & 6 & 4 & $\mathbf{1 0}$ \\
\hline $\mathbf{1 9 - 2 1}$ & 5 & 5 & $\mathbf{1 0}$ \\
\hline Total & $\mathbf{1 5}$ & $\mathbf{9}$ & $\mathbf{2 4}$ \\
\hline
\end{tabular}

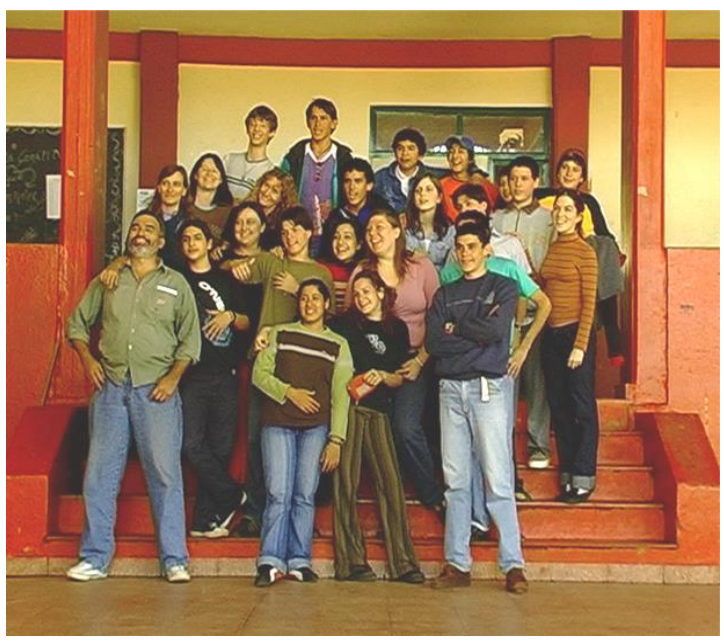

Considerando as idades nas duas oficinas, a maioria dos participantes (40\%) estava na faixa etária 17-18, isto é, na média, nos últimos anos da escola secundária. Em El Soberbio, eram muito mais jovens (duas faixas constituíam $81.3 \%$ do grupo, como mostra o tabela acima) do que em Villa Cabello (83.3\%, englobava as duas faixas dos mais velhos, conforme se constata na tabela acima).

Quanto a sua situação educacional em geral, quase todos os participantes estavam 
no sistema educacional formal. Em El Soberbio, todos os participantes (100\%) estavam frequentando a escola secundária regularmente. Em Villa Cabello, dois terços (16 participantes) eram estudantes do nível secundário, enquanto aproximadamente um terço (7 participantes) estava começando estudos avançados na universidade pública gratuita, e apenas um rapaz abandonou o sistema educacional formal.

Quanto aos seus perfis transculturais gerais,existem alguns fatos peculiares em cada grupo de oficina:

- Em El Soberbio, além de falar espanhol padrão, quase todos falavam português fluentemente, com exceção de Pedro, um menino jovem do povo Mbya Guarani, um grupo étnico indígena, cuja língua materna é Mbya, que encontrou bastante dificuldade em se expressar com fluência em espanhol padrão. Considerando sua família de origem, mais da metade dos participantes era de descendência européia, principalmente alemã.

- Em Villa Cabello, 16 participantes (66\%) estavam relacionados a uma origem espanhola remota, alguns deles também ligados a nacionalidade paraguaia, 7 (29\%) tinham ancestrais europeus, e um, a pais japoneses. Quase todo mundo falava exclusivamente espanhol. Muitos poucos podiam entender Guarani, e um falava um parco japonês.

Levando em conta onde residiam, 4 participantes (25\%) em El Soberbio moravam no campo, e um, em uma comunidade indígena próxima. Em Villa Cabello, todos eram moradores urbanos ou suburbanos, com a particularidade de que dois terços, em tempos recentes, haviam sofrido um processo de realocação forçada com suas famílias, devido ao alagamento da represa de Yacyreta. Este fato provavelmente acarretou uma questão de identidade, como mais tarde ficou expressado em um dos dez filmes.

Basicamente, existiam 3 eixos para entrelaçar durante as sessões, plenamente coincidentes com os objetivos gerais do Projeto:

(a) a questão da percepção dos direitos humanos;

(b) a aprendizagem de ferramentas audiovisuais; e 
(c) o desenvolvimento de laços de comunicação criativa, entre um grupo recém formado de pessoas, que tenha de realizar uma tarefa criativa em conjunto.

De certa forma, essas três grandes linhas poderiam ser majoritariamente relacionadas com as categorias conceituais estruturantes, dos ensaios de comunicação participativa, reunidos pela pesquisadora Shirley White dos EUA, sobre a participação e o desenvolvimento, onde ela os agrupa em três grandes capítulos: a arte de ativação, a arte de técnica, e a arte de construção de comunidade (White, 1999).

Seria útil ilustrar esses 3 eixos com narrações reais à partir de uma perspectiva situacional, a fim de apreender o acúmulo progressivo do poder, resultante desta abordagem participativa. "Empoderamento implica em mudança de relações de poder", afirma White categoricamente (1999: 54), assim identificando o cerne da questão, visto que, é nessa mudança gradual que o empoderamento genuíno começa a surgir lentamente.

Inicialmente, no momento de selecionar escolas como locais para oficinas, nós sabíamos do risco potencial em permitir que a rigidez destes espaços institucionais formais, com o qual geralmente são associados, permeasse essa experiência comunicativa aberta e inovadora. Portanto, desde o início, tomamos muito cuidado de privá-los das suas características usuais. Para este propósito, cada lugar foi constantemente transformado, redefinido, de modo que as atividades pudessem fluir com espontaneidade e liberdade. A biblioteca em Villa Cabello, ou o laboratório de computador em El Soberbio, se modificaria, alternadamente, conforme as atividades praticadas: um pátio, uma lanchonete, um cinema, uma sala de aula, um cenário para filmagem ou uma sala de edição de filme.

Durante todas as oficinas, basicamente nos engajaríamos em conhecer o mundo de cada um, através de atividades que elaboramos intencionalmente despertar a proximidade criativa, usando o intervalo do recreio como ponto de partida para quebrar o gelo, assim como, para gerar uma conexão emocional entre todos, essencial para o suporte do processo pleno por vir.

Foi interessante ver que os momentos de aquecimento físico provaram serem bons meios de se fazer uma ponte entre as faixas etárias, tanto entre eles - um adolescente de 14 difere bastante de um jovem de 21 - quanto entre eles e nós mesmos como os adultos. Os jogos permitiram que aquelas barreiras fossem atravessadas abertamente, rindo e se divertindo, enquanto brincando com movimentos, passos e ritmos, enquanto explicitamente 
percebendo o espaço à nossa volta, com cada um dos nossos 5 sentidos. Assim, foi bastante simples criar um ambiente descontraído e voltado para facilitar a confrontação de idéias; um frutífero encontro de mundos.

\section{Narraç̃a 1: O Prefeito}

(El Soberbio - 3a. sessão)

Começamos esta sessão falando abertamente sobre experiências diárias que provocam desconforto ou raiva. As sessões do primeiro mês tinham como objetivo

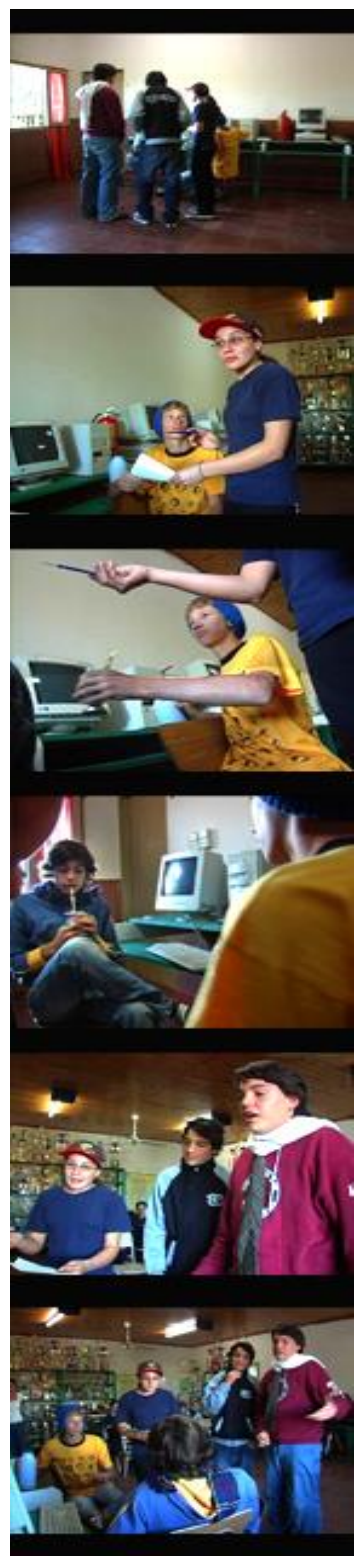
principal inaugurar o diálogo como portal para acordos comuns. Entre as situações levantadas, Damian abordou com paixão a falta de um local urbano decente, onde os jovens pudessem se aglomerar, praticar esportes, se divertir; não somente para os jovens, mas para a comunidade inteira. O tema foi adotado por todos imediatamente. Eles começaram a falar sobre "Poli", o prédio multi-propósito comunitário, cuja construção havia sido iniciada 30 anos atrás, mas que continuava inacabada. Relacionaram isso diretamente à indiferença das autoridades locais - personalizada no Prefeito local - quanto às questões comunitárias. E como El Soberbio é uma cidade muito pequena, eles fizeram toda sorte de anedotas e contos para reforçar suas palavras.

Em seguida, sugerimos que eles dramatizassem nos grupos, algumas das situações angustiantes mais marcantes. Um dos grupos rapidamente selecionou aquela que Damian havia exposto, suscitando que ele desempenhasse o papel do protagonista, que era o Prefeito da sua cidade pequena.

A sequência de dramatização foi simplesmente de tirar o fôlego. Todos os clichês populares associados com o desprezo e desconfiança generalizada, em relação aos políticos e a esfera pública em nosso país, pôde ser claramente percebida ali. A 
situação criada retratou uma professora escolar, com uns poucos alunos visitando o Prefeito, com o objetivo de conseguir a assinatura dele em um "contrato", para concluir a construção do Poli antes do encontro regional esportivo interescolar, a ser realizado no final do ano. Damian como "o político", intencionalmente ignorou o requerimento dos visitantes, fazendo piadas, dando atenção ao seu assistente, oferecendo-lhes algo para beber, e explicitamente os ignorando para atender uma chamada ao celular, um convite de um amigo para uma festa; no fim, simplesmente deixou o contrato para ser assinado por seu assistente, esquivando-se de suas responsabilidades cívicas e do bem estar comunitário.

A cena dramatizada foi um grande sucesso. $O$ restante dos participantes inicialmente riram, quando reconheceram algo que conheciam bem, mas, quando nos reunimos depois, para falar novamente sobre as dramatizações, ficou claro que haviam se sentido aviltados em um direito essencial. Falamos nessa oportunidade, sobre como é necessário às vezes, tornar visível o que usualmente é percebido como "natural", para começar a se tomar providências a respeito.

Para nós facilitadores, enquanto representantes do mundo dos adultos, tal fato mostrou claramente quão cedo e profundamente práticas antidemocráticas podem tornar-se aceitas e internalizadas. E quando no mês seguinte decidiram os temas finais dos filmes, esta situação foi colocada no vídeo de um minuto chamado "Poliiii".

A esse respeito, as palavras do comunicador colombiano Martin-Barbero (2000) são realmente eloquentes quando analisa como os jovens de hoje são expostos a um sistema educacional duplo, o tradicional envolvendo escolas, professores e livros, e o ecossistema comunicativo, composto de fragmentos de informação, geradas e difundidas pela mídia audiovisual, assim como via tecnologias digitais. Esse ambiente permeia a vida dos dias atuais, e exerce sua influência poderosa sobre quase todas as fases da experiência. Assim, educação - educação expandida - deveria ter como objetivo desenvolver cidadãos jovens, que podem aprender a ler todos os fragmentos do mundo, com uma mente crítica e inquisidora, desmontando a inércia usual que costuma encontrar acomodação na riqueza e resignação na miséria. No seu - e no nosso - ponto de vista, não há necessidade de um salvador na sociedade; só há necessidade de sociabilidade, em que viver, negociar e respeitar todos os regulamentos do jogo social, não importando o quanto grande ou pequeno sejam. 
Imagens e sons eram para ser nossas novas ferramentas de empoderamento. Portanto, ao longo de todas as sessões, organizamos atividades tratando deles, até mesmo explicitamente, ou como complemento de algum outro conteúdo. Isto é, se vamos falar de direitos, ou da vida cotidiana, ou de contextos sociais e culturais, nós sempre optamos por introduzir uma contribuição audiovisual - tal como trechos de filmes ou documentários bem conhecidos, por exemplo - para alocar ferramentas audiovisuais à uma posição central no processo de empoderamento.

Portanto, por volta do final do segundo mês, foi necessário começar a aprender as noções básicas da leitura e escrita da linguagem audiovisual, por algum modo de transmissão vertical, já que existia também uma precisa terminologia técnica (tomadas, ângulos, posições, movimentos, etc.) a ser dominada. Portanto, decidimos elaborar uma atividade horizontal antes de nos envolvermos de fato nas questões conceituais. A ideia era reforçar novamente o laço emocional, que naquele momento já vinha tornando-se realmente forte.

\section{Narração 2: A Pequena Janela}

(Villa Cabello - 7a. sessão)

Lara, uma das facilitadoras, veio com um jogo engenhoso. Através de revezamento, dois grupos ficaram de dramatizar duas situações corriqueiras: um condutor de cachorros levando um grupo de cães e um arquiteto construindo uma casa. Quando o primeiro grupo iniciasse sua apresentação teatral, eles seriam subitamente congelados em uma posição um "quadro" - e os participantes do outro grupo explorariam a cena. Nós forneceríamos a eles pedaços de cartolina com pequenas janelas cortadas, através das quais começariam a observar o grupo inteiro, apenas uma parte dele, focariam um detalhe particular, e assim em diante. Em seguida, eles mudariam de posição.

O propósito era vivenciar que podemos - e de fato fazemos- selecionar apenas parte do mundo na nossa frente; o que são nossas ideias, intenções e experiências que orientam nossos pontos de vista, nos obrigando incluir ou excluir certas porções do mundo real. 


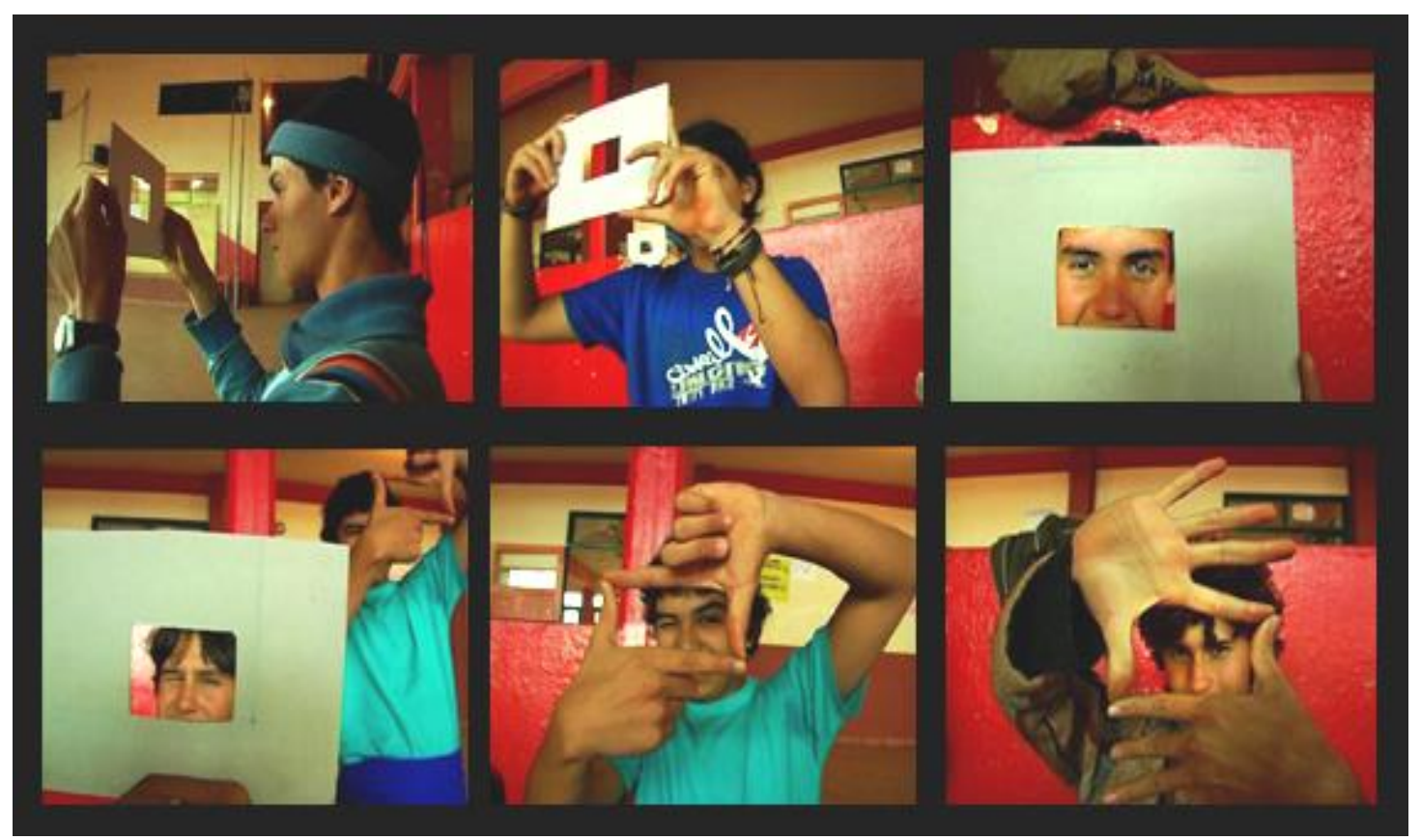

Atrás dessa simples atividade e reflexão houve uma compreensão central: que a tecnologia não é, de forma nenhuma, neutra, e nem suas linguagens e utilizações. Muito pelo contrário. A linguagem das imagens e sons ativa um minucioso processo cognitivo, baseado na conjunção de íntimos significados subjetivos, junto a rigorosas estruturas hegemônicas, reforçando assim sua natureza intrínseca ideológica. Referindo-se novamente à concepção de Paulo Freire (1994), o ato de ler e escrever o mundo - o mundo da linguagem audiovisual para nós - exemplifica precisamente a natureza política da prática educacional.

Para fechar este breve olhar global caleidoscópicoa do nosso processo de empoderamento, há ainda mais uma atividade que nos permitiu delinear uma visão mais profunda desses jovens. Ao se comprometerem à tarefa de dominar a tecnologia pela primeira vez, eles generosamente abriram seus mundos de sonhos para todos nós, seus coparticipantes na oficina. 


\section{Narração 3: Identidade}

\section{(EI Soberbio - Villa Cabello - 10a. sessão)}

A intenção desta atividade teve uma multiplicidade de níveis. Por um lado, um comprometimento individual para contar estórias, já que todos eles preparariam um curto depoimento pessoal a ser compartilhado com todos os participantes da oficina. Por outro lado, há um envolvimento técnico, já que era exigido operar uma videocâmera doméstica, filmando os depoimentos dos seus pares. E um terceiro; incentivar um fluxo de sinergia e empatia, que desenvolveria solidariedade verdadeira durante essas "contribuições" de sentimentos puros para todo o grupo aberto.

Aquele primeiro ensaio de filmagem foi planejado como uma situação quase rudimentar, já que não introduzimos instruções técnicas específicas sobre captura audiovisual, como tomadas de filmagem, enquadramento, etc. Apenas queríamos que os jovens introduzissem e compartilhassem suas contribuições pessoais e/ou experiências no que diz respeito as suas próprias expectativas e auto-explanações. Mais adiante, revisaríamos as gravações coletivamente, produzindo um comentário conjunto sobre o material audiovisual obtido.

Essa é uma seleção de alguns dos seus depoimentos:

\section{FERNANDO}

Se alguém me perguntar sobre mim mesmo, posso dizer umas poucas coisas: por exemplo, que meu nome é Fernando, que tenho 19 anos... me preocupo demais com algumas coisas. Eu sinto ... eu tenho a ideia maluca de mudar o mundo, algo típico de alguém da minha idade. Bem, sinto que vim a este mundo para cumprir uma missão. Ainda não sei bem o que estou fazendo aqui. 


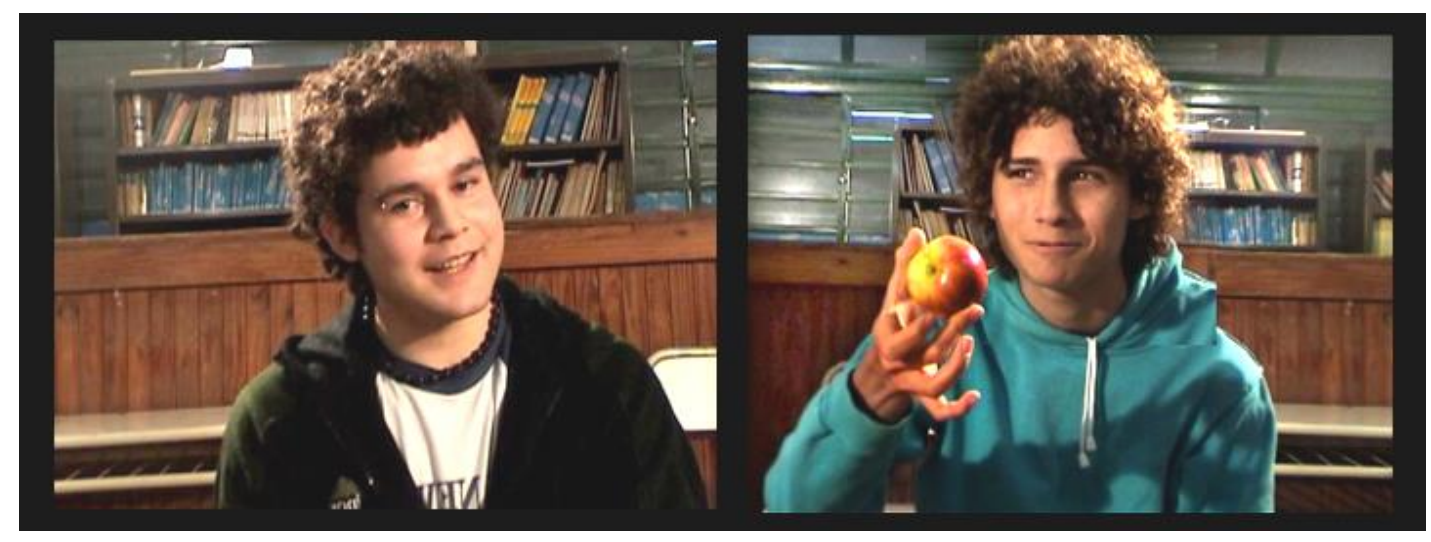

$* * *$

JOEL

Oi, sou Luis Joel. Me chamam de Polo Kleins, mas gosto de ser chamado de Joel. Tenho 17 anos. ... Gosto de dançar. Também gosto de lutar. Gosto muito de meninas, obviamente... Não que alguma vez tenha me apaixonado ... mas há muitas meninas na minha vizinhança que gosto. ... A fruta que mais gosto é maçã ...! (repentinamente, tirando uma maça brilhante do bolso). É minha favorita.

\section{AIMARA (por parte da LARA, sua irmã)}

“Lara: E nós somos as pequenas irmãs Schwieters... Sou Lara e ela é... Aimara: ...Aimara.

Lara: Ela não gosta muito de falar, então falarei ao invés dela..."

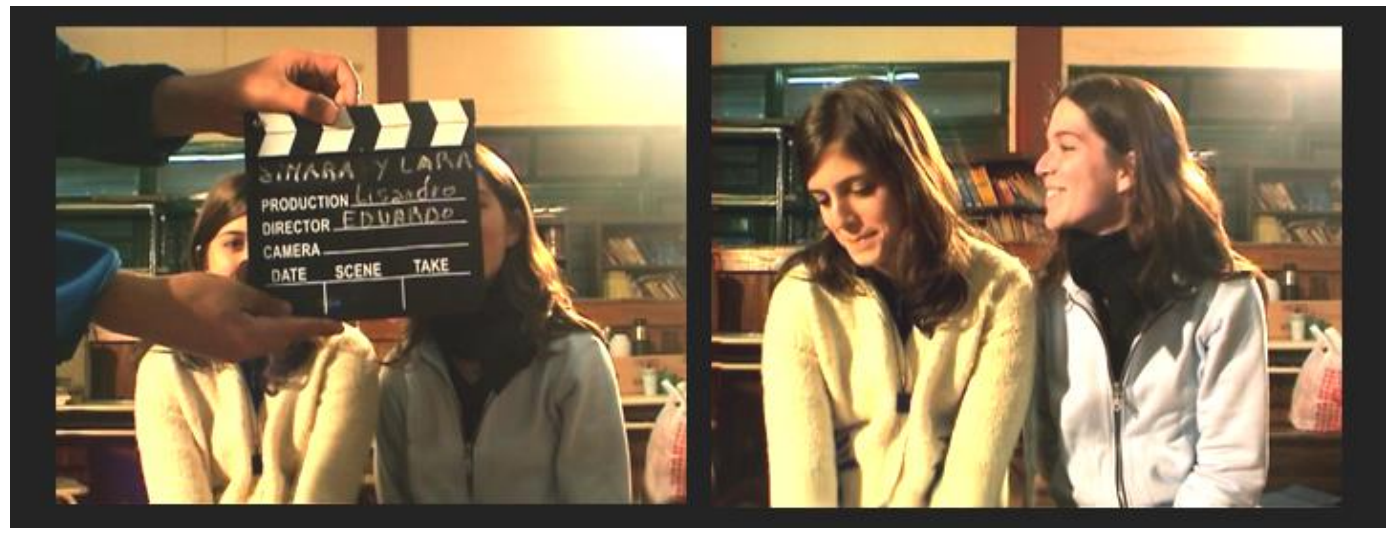




\section{BELEN}

Olá, meu nome é Maria Belen. Participo como voluntaria numa instituição trabalhando com situações relacionadas à saúde sexual; Gosto tanto deste trabalho, preenche minha alma. Sou uma pessoa muito amistosa, embora também curta estar sozinha. Mas não sofrer solidão, pois isto é um dos meus maiores medos.

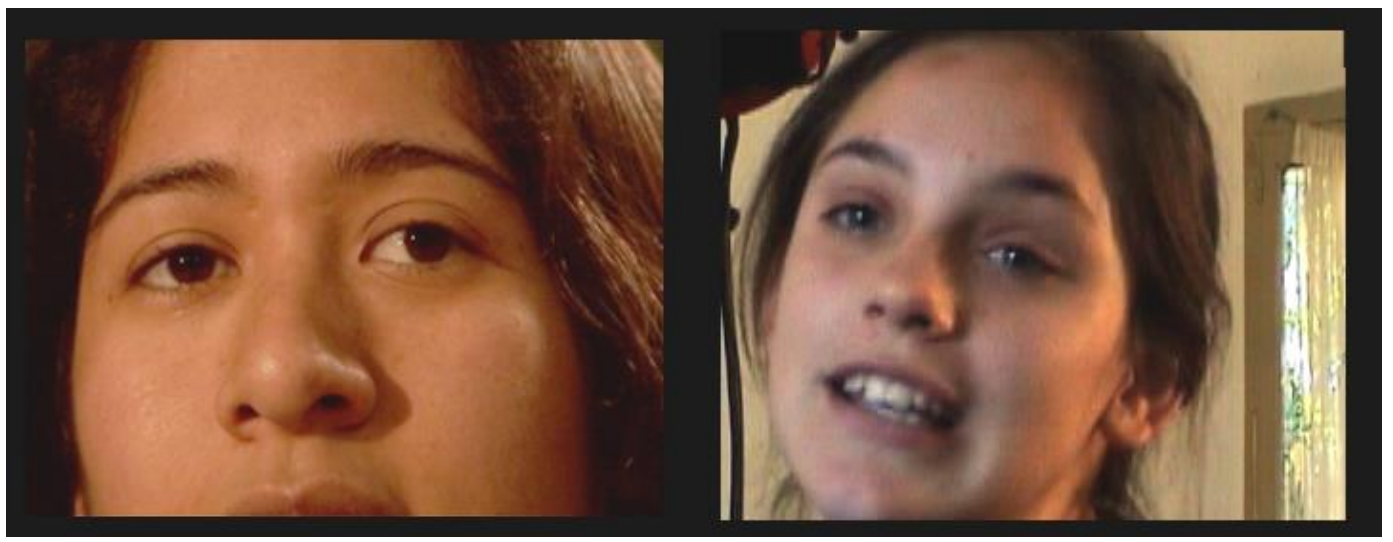

$* * *$

\section{CAMILA}

Oi. Meu nome é Camila, tenho17 anos. Moro em El Soberbio. De fato, moro em dois lugares, aqui e no campo, onde minha família reside ... Gosto de sentir que sou parte de toda esta beleza, embora, ao mesmo tempo, é uma merda completa, por causa de todas as encrencas que temos por aqui. Que mais...? Sim! Também sou a "rainha dos cheiros"... das essências... (todo mundo ri, como acabou de ser coroada rainha nacional da beleza numa produção local agrícola)... E é só. Corta!

\section{PEDRO}

Bem, sou um garoto indígena, vindo de Jejy, uma comunidade perto de El Soberbio, Misiones. Bem, estou estudando agora e gosto de estar com outros jovens aqui na cidade, e ainda com outros da minha aldeia E estou gostando de participar dos nossos 
trabalhos, e também das atividades da escola, a fim de mostrar para as crianças da escola uma imagem da minha comunidade, contando para elas o que é a comunidade, e que nossas culturas são diferentes.

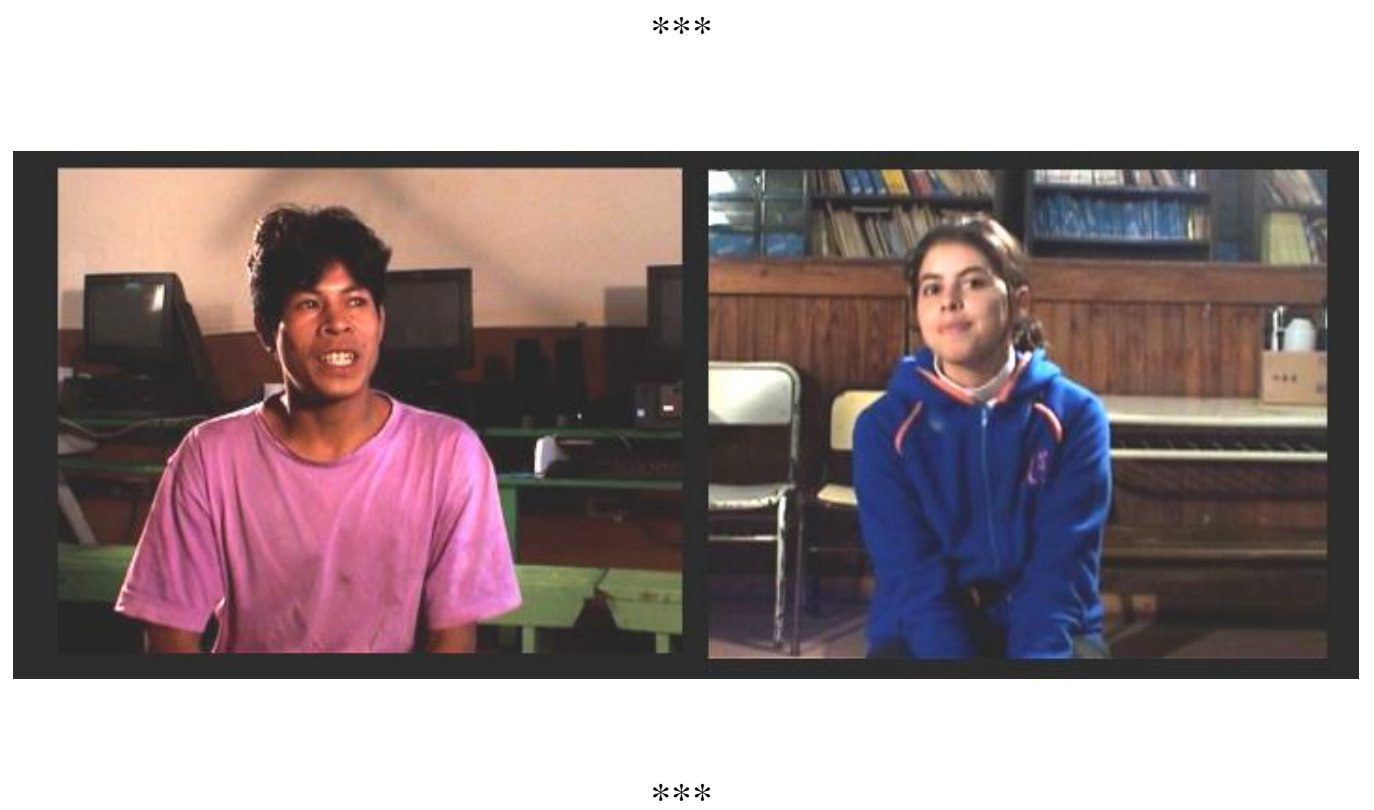

\section{YESICA}

Oi, sou Yesica. Quem sou eu? Uma pergunta enorme. Me defino como tendo uma década e oito anos, como um sonho oculto, como o vento ... que voa suavemente... em busca de seu próprio destino. Sou irmã, sou amiga, sou filha. Estou feliz? Sim, estou; como meus amigos na escola, fazendo o que gosto de fazer. Sempre penso em mim como uma mancha que não deveria desaparecer, porque sonha e vive. Sou como uma guerra, um desafio, sempre questionando e buscando meu euverdadeiro. Essa sou eu.

Seja contado por eles próprios ("Oi. Eu sou...", como a maioria deles começou) ou pelas palavras de outros ("Ela é...", disse Lara); seja altamente exposto ("Essa sou eu.", expressa Yesica de forma desafiadora) ou simplesmente se mesclando em uma identidade mais ampla (Pedro nunca nos diz seu nome; apenas que pertence a sua comunidade), essa questão crucial da identidade autopercebida inspira, ativa, mobiliza. Um simples ensaio de filmagem poderia se transformar em uma ponte para o mundo do outro, guiada pelas palavras do outro.

E essa é obviamente a estratégia cognitiva usada durante os exercícios progressivos, tanto os refletivos, quanto os audiovisuais. O que fizemos foi dar espaço ao oculto e fazer com que emergisse como contribuição valiosa para atividade em grupo. Dando enfoque a 
essa participação, as 10 linhas de estória foram, em seguida, coletivamente acordadas e desenvolvidas, seus roteiros escritos, suas sequências preproduzidas e filmadas, e, um mês mais tarde, foram editadas e compartilhadas com suas próprias comunidades. Em seguida, UNICEF e KINE organizariam uma exposição a nível nacional, e facilitariam maior difusão via televisão, de modo a permitir que estes pontos de vista tivessem um alcance ampliado.

O programa "Un Minuto por Mis Derechos” também havia projetado um esquema paralelo de avaliação global com a primeira exposição oficial de todas as peças de vídeo num cinema importante, na capital Buenos Aires. Todos os participantes na Argentina eram esperados lá para uma reunião de dois dias, durante a qual todos se conheceriam e seguiriam um procedimento de avaliação já projetado. Com o propósito de garantir a participação de todos, o programa ofereceu hospedagem e alimentação em Buenos Aires, enquanto as despesas de viagem seriam cobertas pelo governo local. Infelizmente, as autoridades provincianas em Misiones deixaram de proporcionar o apoio esperado, principalmente, devido ao fato de um processo de votação política estar acontecendo precisamente naquela época, o que acabou causando profunda decepção e desespero nos jovens.

Foi o único grande contratempo real que nós - jovens e facilitadores - tivemos que enfrentar durante o processo, e, apesar de tentamos fazer de tudo para superá-lo, não fomos capazes de encontrar uma outra maneira apropriada para cobrir os custos de viagem.

Porém, esta situação triste não representou uma interferência séria em tudo que já havia sido desenvolvido entre eles durante as oficinas, pois a maioria deles mantem relações estreitas até hoje, enquanto uns poucos - três de Villa Cabello e um de El Soberbio - conseguiram reencontrar-se no ano seguinte e filmar alguns documentários curtos e estórias sobre as dificuldades enfrentadas pelas bases das suas comunidades.

Estas pequenas estórias experienciais sobre nosso processo participativo pretenderam apenas ilustrar nossa abordagem como catalisadores e facilitadores do mesmo. Elas obviamente não explicam tudo que ocorreu. Colocando em palavras o que passamos com tanta intensidade, nunca se faria jus ao entrelaçamento real desenvolvido lá. Mas, espero que possa proporcionar pelo menos uma idéia aproximada do modo como as coisas aconteceram durante nossas duas oficinas, dentro da proposta "Um Minuto por Mis 
Derechos" 5 .

Juntando experiência com as linhas teóricas já citadas, o processo proporcionou uma chance de agregar diálogo com diversidade cultural; a primeira, como um caminho aberto para abordar cada meta perseguida enquanto o processo foi evoluindo; a segunda, a medida que as ricas configurações permitiram que os jovens identificassem suas condições contextuais, desempenhando um papel favorável no desenrolar do programa.

E embora esse programa de desenvolvimento social seja essencialmente uma proposição de cima para baixo (orientada para produto, restrições de tempo rigorosas, entre outras características já mencionadas), sua metodologia envolve uma abordagem participativa, permitindo auto-respeito e promovendo compreensão mutua. Como todos estão igualmente engajados em um processo tão complexo quanto fazer filmes, a sensação de colaboração conjunta e organizada pode levar a um resultado digno e ser vivido plenamente.

Quanto às ferramentas audiovisuais - embora de alguma forma possam não parecer centrais nessas sequências narradas - juntas elas constituíram uma forte sequência de empoderamento, colocando em movimento uma cadeia participativa de escolhas, decisões e ações, culminando na própria construção dos filmes.

Dez curtos filmes impactantes que falaram sobre direitos para um acesso aberto a educação, viver em um ambiente bem cuidado, evitar gravidez e a prostituição de meninas jovens, viver sob um teto seguro, desenvolver raízes profundas com pessoas e lugares, encontrar ambientes com famílias compreensíveis, serem considerados como iguais e serem escutados.

Além disso, todos os participantes puderam sentir que têm uma voz e um ponto de vista, e que têm um valor real. E o que talvez seja o mais significativo; a possibilidade de compreender que podemos aprender das certezas, mas certamente podemos aprender muito das dificuldades e das dúvidas que surgem da própria vida, num processo progressivo.

\footnotetext{
5 Todos os videominutos argentinos podem ser acessados e assistidos no site da KINE: http://www.1minutoxmisderechos.org.ar. Os dez filmes que produzimos em El Soberbio e Villa Cabello (Misiones, 2006), também podem ser acessados e/ou baixados do site: www.misiones.gov.ar/infomisiones/4PRO/minuto/index.htm.
} 


\section{Referências}

ABINZANO, Roberto. “Globalizacion, Regiones y Fronteras". In: Debate documento ${ }^{o}$ 27. MOST: UNESCO, 1998. Disponível em: http://www.unesco.org/most/abinzano.htm. CAMBLONG, Ana; SKUPIEN, Ines; LIRUSSI, Marta; DAVIÑA, Liliana y SANTANDER Carmen. Consideraciones generales acerca de la situacion linguistica en la Provincia de Misiones. Misiones: Facultad de Humanidades y Ciencias Sociales/ UNaM, 1996.

FREIRE, Paulo. Pedagogia da Esperança. Um reencontro com a Pedagogia do oprimido. São Paulo: Editora Paz e Terra, 1997. Disponível em: http://intranet.uds.edu.py:81/biblioteca/Livros\%20Teolog\%C3\%ADa/PAULO\%20FREIRE \%20-\%20PEDAGOGIA\%20DA\%20ESPERANÇA.pdf.

KINE Fundação. "Aumentar las Miradas es Aumentar el Mundo". In: UN-Habitat Best Practices Database. Nairobi: United Nations Human Settlements Programme, 2006. Disponível em: http://staging.unchs.org/bestpractices/2006/mainview.asp?BPID=664.

MARTIN-BARBERO, Jesus. "Jovenes: Comunicacion e Identidad". In: Pensar Iberoamerica - Revista de Cultura, Número 0. Madrid: OEI, 2002.

http://www.comminit.com/en/node/149764 http://www.oei.es/pensariberoamerica/ric00a03.htm

REGUILlO, Rossana. Pensar en el mundo en y desde America Latina. Desafio intercultural y politicas de representacion. Barcelona: IAMCR, 2002. Disponível em:

http://www.portalcomunicacion.com/catunesco/esp/3/down/reguillo/reg.pdf.

WHITE, Shirley A. Participatory Video. Images that Transform and Empower. New York: Sage Publications Pvt. Ltd, 2003.

WHITE, Shirley A. The Art of Facilitating Participation. Ithaca: Cornell University, Sage Publications Pvt.Ltd, 1999.

Recebido em: 30/11/2012

Aprovado em: 28/01/2013

ANA ZANOTTI. Mestrado em "Comunicação para o Desenvolvimento" (Malmö Högskola, Suecia). Graduação em Antropologia Social (Universidade Nacional de Misiones, Argentina, 1996) e cineasta de documentários. Suas primeiras experiências audiovisuais foram nos programas de aprendizagem à distância no Sistema de Teleducação e Desenvolimento (SIPTED), um programa de serviço público administrado pelo Ministério da Educação em Misiones (Arg.). Em 1990, se engajou plenamente em escrever e dirigir projetos de filmes independentes, alguns dos quais foram selecionados - e, às vezes, premiados - por vários eventos internacionais de filmes documentários, tais como suas 4 séries de documentários para TV, ESCENAS DE LA VIDA EN EL BORDE, relacionados a diversos encontros culturais ou "bordes", através da vida cotidiana dentro de uma região fronteiriça de 3 países (Argentina, Paraguai e Brasil). Também organiza e conduz oficinas criativas com jovens, sobre pesquisa documental e a realização de filmes, tal como esta experiência argentina narrada aqui, como também através de laboratórios intensivos no sul da Espanha (CIC-Bata, em Andaluzia, 2008, 2009 e 2010), abordando experiências de vida transculturais. 